\title{
A physiotherapy triage assessment service for people with low back disorders: evaluation of short-term outcomes
}

This article was published in the following Dove Press journal:

Patient Related Outcome Measures

13 June 2012

Number of times this article has been viewed

\author{
Brenna Bath \\ Punam Pahwa \\ College of Medicine, University of \\ Saskatchewan, Saskatoon, Canada
}

Correspondence: Brenna Bath School of Physical Therapy, College of Medicine, University of Saskatchewan, II I College Drive, Saskatoon, Canada, S7N 0W3

Tel +I 3069666573

Fax +l 3069666575

Email brenna.bath@usask.ca
Purpose: To determine the short-term effects of physiotherapy triage assessments on selfreported pain, functioning, and general well-being and quality of life in people with low backrelated disorders.

Methods: Participants with low back-related complaints were recruited from those referred to a spinal triage assessment program delivered by physiotherapists (PTs). Before undergoing the triage assessment, the participants completed a battery of questionnaires covering a range of sociodemographic, clinical, and psychosocial features. The study used the Numeric Pain Rating Scale (NPRS), the Oswestry Disability Index (ODI), and the Medical Outcomes Survey 36-item short-form version 2 (SF-36v2) to assess self-reported pain, function, and quality of life. Baseline measures and variables were analyzed using a descriptive analysis method (ie, proportions, means, medians). Paired samples $t$-tests or Wilcoxon matched-pair signedrank tests were used to analyze the overall group differences between the pretest and posttest outcome measures where appropriate.

Results: A total of 108 out of 115 (93.9\%) participants completed the posttest survey. The Physical Component Summary of the SF36v2 was the only measure that demonstrated significant improvement $(P<0.001)$.

Conclusion: A spinal triage assessment program delivered by PTs can be viewed as a complex intervention that may have the potential to affect a wide range of patient-related outcomes. Further research is needed to examine the long-term outcomes and explore potential mechanisms of improvement using a biopsychosocial framework.

Keywords: interprofessional practice, quality of life, back pain, orthopedics

\section{Introduction}

Low back pain (LBP) and low back-related disorders are significant population health problems ${ }^{1-3}$ that consume a large amount of health care resources. ${ }^{4-6}$ Patients with a variety of low back-related complaints comprise a large proportion of referrals made to orthopedic surgeons. ${ }^{7,8}$ Many of these patients are not considered surgical candidates ${ }^{9,10}$ and may simply require reassurance that they do not have serious spine pathologies. ${ }^{11,12}$ This patient subgroup contributes significantly to consultation wait times, which ultimately leads to greater wait times for other orthopedic surgical procedures such as hip and knee joint replacements. Reducing the number of nonsurgical consultations in a surgeon's caseload will help to reduce consultation wait times for surgical patients who may benefit from spinal surgery and potentially redirect nonsurgical candidates for more appropriate treatment earlier. An alternative approach to this problem is setting up collaborative work relationships between primary health care providers who have 
expertise in the assessment and evaluation of musculoskeletal disorders and orthopedic surgeons.

Models of care provision for patients with musculoskeletal problems that involve nonsurgical specialists or other healthcare professionals collaborating with surgeons are increasingly common in the literature. ${ }^{13-16}$ Physiotherapists (PTs) with advanced orthopedic training, who practice with a maximized or extended scope, have been shown to be equally as effective as orthopedic surgeons in diagnosis and nonsurgical management of many musculoskeletal conditions. ${ }^{13,17-21}$ PTs performing this role have also contributed to reduced wait times and improved referral practices. ${ }^{13,22}$ Data from the United Kingdom (UK) indicate that pre-screening of patients by physiotherapists can more than double the proportion of patients who truly need surgery on assessment by the surgeon. ${ }^{23}$

This type of arrangement can be referred to as triage, ${ }^{24}$ whereby patients are first screened to determine if they require referral to a surgeon, a recommendation for further conservative management, and/or further diagnostic investigations. However, the evaluative research examining these types of programs is sparse. The few programs studied focus on general musculoskeletal practices ${ }^{13,25,26}$ or hip and knee joint arthritis screening and management only. ${ }^{15,27,28}$ The literature describes and evaluates few triage services delivered by PTs that focus solely on spinal conditions. ${ }^{22,29}$ Furthermore, a systematic review examining the evidence of extended roles for a variety of allied health professionals concluded that much of the research fails to focus on the health outcomes of patients. ${ }^{30}$ Despite research demonstrating the effectiveness of PTs with advanced orthopedic training in similar roles, ${ }^{13,22,27}$ little is known about the potential impacts of a spine triage program delivered by PTs on multidimensional patient-related outcomes.

A triage assessment program delivered by PTs can be viewed as a complex intervention ${ }^{31}$ that may have the potential to influence a wide range of patient-centered outcomes. ${ }^{32}$ This type of program is an example of a change in service delivery and organization that goes beyond a simple intervention as it includes several components that may affect outcomes. As such, a phased approach to the evaluation of such complex interventions is recommended. ${ }^{31}$

The purpose of this study is to determine the short-term (ie, 4 weeks) impacts of a physiotherapy triage assessment on self-reported pain, perceived functional status, physical and psychological well-being, and quality of life for people with low back-related disorders. We chose the 4-week posttest timeframe to allow enough time for the assessment report and recommendations to reach the primary care provider. This period is also short enough that any treatment recommendations are unlikely to have been carried out, which provides an indication of whether any changes in patient outcomes could be attributed to the assessment process itself.

\section{Methods}

\section{Background: spinal triage service}

The Spinal Triage Assessment Service (STAS) is a collaborative effort between a group of three orthopedic surgeons and PTs from a private rehabilitation clinic located in a mid-size Canadian city. The program was initiated to address the excessive number of referrals the orthopedic surgeons were receiving of patients with low back-related conditions who did not require surgery. Prior to the initiation of the program, the surgeons expressed frustration regarding how long their patients were waiting to see them (often over a year) and the high proportion of nonsurgical referrals in their caseloads. The surgeon group had an existing extensive working relationship with PTs through the rehabilitation clinic and approached the clinic to request help with their wait-list backlog and the screening of subsequent referrals pertaining to spinal (mainly low back-related) conditions. All the PTs involved in the STAS completed advanced orthopedic training in the Canadian Orthopaedic Syllabus, with experience ranging from 5 to 30 years. At present, any patients referred to the orthopedic surgeons for spinal problems are automatically rerouted to the PTs for screening. Figure 1 shows the STAS referral and clinical pathways.

The assessing PT discusses the findings of each assessment with the PT consultant via videoconferencing with the patient present (Figure 2). The clinical diagnosis and recommendations are determined jointly between the assessing PT and the consultant PT through a collaborative reasoning

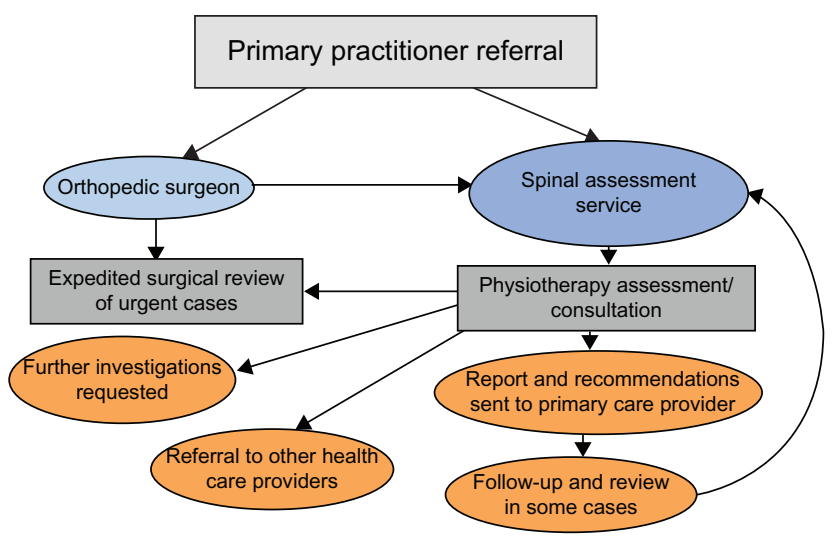

Figure I STAS referral, assessment, and clinical pathways. Abbreviation: STAS, Spinal Triage Assessment Service. 


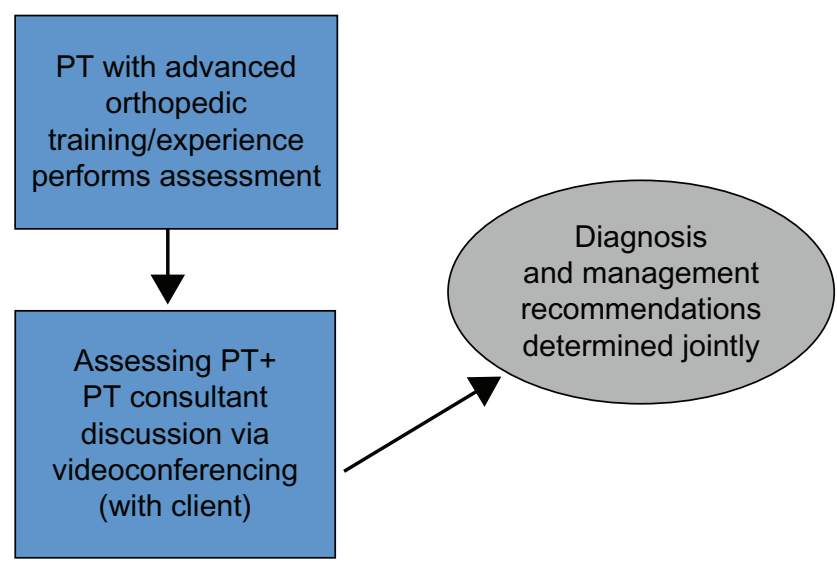

Figure 2 STAS assessment process.

Abbreviations: PT, physiotherapist; STAS, Spinal Triage Assessment Service.

approach $^{33}$ with input from the patient. A detailed report outlining the assessment findings, diagnosis, management recommendations, and any further diagnostic tests is then sent to the referring health care providers and any other relevant care providers involved. It is worth mentioning that the consultant PT had an extensive prior working relationship with the orthopedic surgeon group.

\section{Participants}

The participants of the study were recruited over an 8 -month period from patients referred to the triage program either directly from their primary care provider or via one of the participating orthopedic surgeons. The inclusion criteria included patients referred to the triage program with primarily low back-related complaints, age $\geq 18$ years and $\leq 80$ years, and provision of informed consent. The exclusion criteria included patients receiving third-partypayer funding (ie, Worker's Compensation Board, or other) for their back-related complaints, patients with primarily neck- (cervical spine) or mid back-related (thoracic spine) complaints and people with language, reading, or comprehension barriers that would limit adequate completion of the study paperwork. Patients were also excluded due to other reasons such as scheduling conflicts or other medical issues.

The patients were screened on the phone for the inclusion and exclusion criteria as well as for their potential willingness to participate in the study after their spinal triage assessment was booked. Potentially eligible patients received a letter from the researchers outlining the study and were asked to arrive 1 hour early for their assessment to meet with one of the researchers. Potential participants were provided with a $\$ 10$ gift card upon arrival at their booked appointment. The gift card was given to all potential participants regardless of whether they met the inclusion criteria or chose to participate. The primary researcher conducted further screening for eligibility before the participants completed the informed consent process. A PT who was indirectly involved with the research collected select demographic and clinical characteristics from the nonparticipants and provided this data in a de-identified manner to the researchers.

\section{Study design}

This study uses a quasi-experimental, one group pretestposttest design. ${ }^{34}$ This design is the best option for evaluating the program under examination since there is no accessible and equivalent control group that can be used for comparison. The "pretest" measures were derived from a paper-based survey that was completed before the participants underwent the triage assessment as well as from a clinical classification tool completed by the assessing PT. The Measures section outlines this process in detail. The posttest evaluation of outcomes was completed approximately 4 weeks after the assessment through mail or a password-protected online survey (as per the participant's preference). Reminders for completion of the participant follow-up surveys were conducted by phone or email prompt (up to three reminders approximately one week apart) on the basis of the tailored design method proposed by Dillman et al. ${ }^{35}$ The Behavioural Ethics Board of the University of Saskatchewan approved the ethics of this study.

\section{Measures}

Before undergoing the triage assessment, the participants completed a battery of questionnaires covering a range of variables including sociodemographics, clinical features, fear avoidance beliefs, depression, and somatization. A detailed description of these intake variables is beyond the scope of this paper. The assessing PT completed a clinical classification tool that categorized the "diagnosis" and management recommendations for each participant. ${ }^{36} \mathrm{~A}$ description of the outcome measures (completed at intake/pretest and the 4-week/posttest) is presented below.

\section{Self-perceived pain}

The eleven-point Numeric Pain Rating Scale (NPRS) ranges from zero ("no pain") to ten ("worst pain imaginable") and was used to indicate the intensity of current pain and at its best and worst level over the last 24 hours. ${ }^{37}$ The average of these three ratings provided the overall pain score. The scale is proven to have adequate reliability, validity, and 
responsiveness in patients with LBP when the three scores are averaged to produce one score. ${ }^{38}$

\section{Self-perceived function}

Self-perceived function was assessed with the modified Oswestry Disability Index (ODI), which is a conditionspecific self-report questionnaire. ${ }^{39,40}$ Items on the ODI focus on how much LBP is limiting activities of daily living such as sitting, standing, walking, and lifting. The ODI used in this study was modified from its original form by substituting a section regarding employment/home making ability for a section related to sex life since such questions are commonly left unanswered by respondents. The modified version of the ODI has been found to have high levels of reliability (intraclass correlation coefficient $[\mathrm{ICC}]=0.90)$ and responsiveness in patients with $\mathrm{LBP}^{40,41}$ The ODI is known as the most useful method in specialty care settings or in situations where the patient's disability level is likely to remain relatively high throughout a trial. ${ }^{42}$ Higher scores on the ODI represent higher levels of perceived disability. Fairbank et al ${ }^{39,40}$ suggest that the continuous scores can be categorized into five categories of perceived disability - "minimal," "moderate," "severe," "crippled," and "bedbound"/"exaggerating." Since there were no participants with ODI scores in the highest disability category in this study, the last category was eliminated in our analysis.

\section{Quality of life and general health status}

The Medical Outcomes Survey 36-item short-form survey version $2\left(\mathrm{SF}-36 \mathrm{v} 2^{\circledR}\right.$ ) (Quality Metric Incorporated, Lincoln, RI, USA $)^{43}$ was used to assess the general health status of the participants. The measure is comprised of eight interrelated health dimensions including physical functioning, rolelimitations resulting from physical health problems, bodily pain, general health, vitality (ie, energy/fatigue), social functioning, role-limitations resulting from emotional problems, and mental health (ie, psychological distress and psychological well-being). ${ }^{43,44}$ Two component summaries (ie, physical and mental) can be derived from the eight subscales. ${ }^{43}$ The SF-36v2 ${ }^{\circledR}$ is a valid and reliable measure for both clinical and general populations ${ }^{45-47}$ and is a recommended measure for people with back pain. ${ }^{48}$ The SF-36v ${ }^{\circledR}$ is shown to have improved reliability over the previous SF-36 version as well as improved floor and ceiling effects in certain domains. ${ }^{43,49}$ The SF-36v2 ${ }^{\circledR}$ was scored by transforming raw scores into norm-based scores for each of the subscales and weighting each subscale to produce physical and mental component summaries (PCS and MCS). ${ }^{43}$ Thus, higher scores represent greater health status and quality of life.

\section{Analysis}

The descriptive analysis of all the baseline measures and variables included frequencies and valid percentages for categorical variables and mean, standard error, median, and interquartile ranges for continuous variables. The ShapiroWilk Test was used to numerically assess the normality of the distribution of each continuous variable. Variables that adhered to a normal distribution were evaluated with parametric tests (eg, $t$-tests) and variables that were significantly different (ie, $P>0.05$ ) from the normal distribution were evaluated with nonparametric test equivalents (eg, Mann-Whitney U). All significant tests were 2-tailed and alpha was set at $\alpha=0.05$ (unless otherwise stated).

Differences in the select demographic and clinical variables between participants and nonparticipants (ie, those that were eligible to participate but chose not to) as well as between respondents and nonrespondents for the posttest were evaluated using a Chi-square or Fisher's exact test for categorical variables. Independent samples $t$-test or the Mann-Whitney U test were used for continuous variables.

General group (mean or median) differences between the baseline and posttest outcome measures were evaluated with paired-sample $t$-tests (for variables that were normally distributed at each time point) or Wilcoxon matched-pair signed-rank tests (for variables that were non-normally distributed at each time point). A Bonferonni correction (ie, $0.05 /$ number of comparisons) was applied to alpha to protect against making a type 1 (ie, false positive) error due to multiple comparisons. Comparisons were made between the prettest and posttest scores of the NPRS, the ODI, and the eight subscales of the SF-36v2 $2^{\circledR}$ (ie, physical function, physical role, bodily pain, general health, vitality, social function, emotional role, mental health) as well as the PCS and MCS scores of the SF-36v2 ${ }^{\circledR}$. Therefore, the new alpha level was set at $0.05 / 12=0.004$. All statistical analysis was conducted using PASW (Predictive Analytics SoftWare) Statistics Mac version 18.0 (SPSS Inc., IBM Corporation, Armonk, NY). This study was approved on July 30, 2009 by the Behavioral Ethics Board of the University of Saskatchewan.

\section{Results}

\section{Participants versus nonparticipants}

The study's intake period spanned 8 months (October 2009 to June 2010). During this time, 198 people had an assessment through the triage program, 56 people were excluded (Table 1), 
Table I Reason for exclusion from study

\begin{tabular}{|c|c|}
\hline Reason & Frequency (\%) \\
\hline Age $>80$ or $<18$ & $7 / 56(12.5)$ \\
\hline Third-party-payer funded ${ }^{\mathrm{a}}$ & $14 / 56(25.0)$ \\
\hline Symptom location (ie, not lumbar spine region) & $13 / 56(23.2)$ \\
\hline Did not attend & $4 / 56(7.1)$ \\
\hline Assesment type $\mathrm{e}^{\mathrm{b}}$ & $6 / 56(10.7)$ \\
\hline Otherc & $12 / 56(2 \mid .4)$ \\
\hline \multicolumn{2}{|c|}{$\begin{array}{l}\text { Notes: aWorker's Compensation Board or other third-party insurance company; } \\
\text { 'person already saw a surgeon, surgeon asking for PT opinion regarding further } \\
\text { conservative treatment options; cincludes scheduling conflicts and other medical } \\
\text { (eg, medical urgency/emergency unrelated to spine assessment, scheduled for joint } \\
\text { replacement during study period). }\end{array}$} \\
\hline Abbreviation: PT, physiotherapist. & \\
\hline
\end{tabular}

and 27 people who met the inclusion criteria chose not to participate. This left 115 participants, and an overall response rate, among those who were eligible of $81.0 \%(115 / 142)$. Among the participants, 66/115 (57.4\%) opted to complete a mailed paper-based follow-up survey and 49/115 (42.6\%) chose to complete an online password-protected follow-up survey. There were no significant differences $(P>0.05)$ between patient participants and nonparticipants in age, sex, diagnosis, or management recommendations.

\section{Description of study sample}

Descriptive statistics of demographic, employment and general health variables of the study sample can be found in Table 2 (continuous demographic variables), Table 3 (categorical demographic and employment characteristics), and Table 4 (categorical general health variables).

The median age of the participants was 51 years, $48.7 \%$ were female, and three quarters of participants were married (74.8\%). The majority of the participants $(55.6 \%)$ had an educational attainment higher than grade 12, an annual household income greater than CAD \$30,000 (81.6\%), fullor part-time employment (68.7\%), and a "rural" residence (70\%). Moreover, a sizeable proportion of the participants were farmers $(27.8 \%)$. The majority $(73.9 \%)$ of the sample had body mass index scores greater than a "normal" range, ${ }^{50}$ $61.2 \%$ used to smoke or were current smokers, and 58.2\% had two or more other chronic health conditions with "other bone or joint problems" the most prevalent condition reported
(62.6\%). Approximately half (50.8\%) of the participants were in the "at risk" category, which was determined using the Distress and Risk Assessment Method (DRAM). ${ }^{51}$ This measure indicates psychological risk of depression and/or somatization with $17.4 \%$ scoring as "distressed" due to either somatic or depressive symptoms. Most participants (79.2\%) had "moderate" to "severe" perceived disability according to the categorized ODI scores.

Table 5 presents the clinical descriptors of the study sample. Most participants reported relatively long total duration of their symptoms $(74.8 \%>24$ months) and current episode duration. The majority of participants had previously attempted a variety of noninvasive or conservative treatment modalities including medication, massage therapy, chiropractic, and physiotherapy. Relatively few participants (3.5\%) reported past surgical intervention for their back problems. The majority of the participants also reported having below knee symptoms (59.1\%) indicating potential nerve root involvement. Table 5 also provides a summary of the categorization used by the assessing PT of the clinical features including a clinical classification tool. ${ }^{36}$ The majority of participants were classified as having a "problem in back" (93.9\%); however, there was a relatively high proportion of participants who were classified as having "medical" (9.6\%) and "spinal cord/cauda equina" $(4.3 \%)$ presentations. Similarly, categorization according to the LBP triage categories demonstrated relatively high proportions of "nerve root problems" (47.0\%) and "serious spine pathology" (7.0\%). Further PT treatment was recommended in the majority of cases $(63.5 \%)$ and "referral to the surgeon" was made in $20 \%$ of cases.

A total of $108 / 115$ participants $(93.9 \%)$ completed the posttest survey. Table 6 compares the select characteristics of the respondents and nonrespondents. The only significant difference between these groups was "residence" with proportionately more nonrespondents having an "urban" residence $(P=0.039)$.

Table 7 presents an overall group mean or median comparison between the prettest and posttest outcome measures. When the alpha level was adjusted by a Bonferonni

Table 2 Demographics of study sample (continuous variables)

\begin{tabular}{|c|c|c|c|c|c|c|}
\hline Variable & Min & Max & Mean & SE & Median & IQR \\
\hline Age (years) & 20 & 79 & 51.69 & 1.263 & 51.00 & $43.0-62.0$ \\
\hline Symptom total duration (months) & I & 480 & 138.94 & $12.06 \mid$ & 108.00 & $28.5-240$ \\
\hline Current episode duration (months) & I & 408 & 39.54 & 6.796 & 10.00 & $4.0-36.0$ \\
\hline Body mass index (kilogram/meter $\left.{ }^{2}\right)$ & 18.75 & 58.39 & 28.84 & 0.626 & 27.32 & $24.4-31.6$ \\
\hline
\end{tabular}

Abbreviations: Min, minimum; Max, maximum; SE, standard error; IQR, interquartile range. 
Table 3 Demographic and employment characteristics (categorical variables)

\begin{tabular}{|c|c|}
\hline Variable & Frequency (\%) \\
\hline \multicolumn{2}{|l|}{ Age quartiles } \\
\hline$<43$ yrs & $29 / 115(25.2)$ \\
\hline $43-51$ & $31 / 115(27.0)$ \\
\hline $52-62$ & $31 / 115(27.0)$ \\
\hline$>62$ & $24 / 115(20.9)$ \\
\hline \multicolumn{2}{|l|}{ Age } \\
\hline$<50$ yrs & $53 / 115(46.1)$ \\
\hline Female & $56 / 115(48.7)$ \\
\hline \multicolumn{2}{|l|}{ Marital status } \\
\hline Married & $86 / 115$ (74.8) \\
\hline Separated & $1 / 115(0.9)$ \\
\hline Divorced & $8 / 115(7.0)$ \\
\hline Widowed & $4 / 115(3.5)$ \\
\hline Never married & $16 / 115(13.9)$ \\
\hline \multicolumn{2}{|l|}{ Education } \\
\hline Did not complete grade 12 & $21 / 115(18.3)$ \\
\hline Completed grade 12 & $30 / 115(26.1)$ \\
\hline Trade school & $34 / 115(29.6)$ \\
\hline Some university & $19 / 115(7.8)$ \\
\hline University degree & $9 / 115(7.8)$ \\
\hline Graduate degree & $2 / 115(1.7)$ \\
\hline \multicolumn{2}{|l|}{ Income (CAD) } \\
\hline$<\mathrm{I5K}$ & $10 / 109(9.2)$ \\
\hline $15 K-29,999$ & $10 / 109(9.2)$ \\
\hline $30 K-59,999$ & $38 / 109(34.9)$ \\
\hline $60 K-99,999$ & $31 / 109(28.4)$ \\
\hline$\geq 100 \mathrm{~K}$ & $20 / 109(18.3)$ \\
\hline \multicolumn{2}{|l|}{ Employment } \\
\hline Paid full time & $62 / 115(53.9)$ \\
\hline Paid part time & $17 / 115(14.8)$ \\
\hline Unemployed & $5 / 115(4.3)$ \\
\hline Homemaker & $9 / 115(7.8)$ \\
\hline Disabled & $4 / 115(3.5)$ \\
\hline Student & $2 / 115(1.7)$ \\
\hline Retired & $16 / 115(13.9)$ \\
\hline Not working due to back pain & $22 / 115(19.1)$ \\
\hline Back pain caused by work & $42 / 115(36.5)$ \\
\hline Rural $^{a}$ & $77 / 115(70.0)$ \\
\hline Farmer & $32 / 115(27.8)$ \\
\hline
\end{tabular}

Note: ${ }^{2}$ Rural residence defined as weak or no Metropolitan Influenced Zones. ${ }^{67}$

correction (ie, $0.05 / 12=0.004$ ), the only measure that demonstrated overall significant improvement was the PCS of the SF-36v $2^{\circledR}(P<0.001)$. However, without the adjustment to alpha, there was also significant improvement $(P=0.007)$ of the bodily pain scale of the SF-36v2 ${ }^{\circledR}$ (SF_36_BP) and NPRS scores $(P=0.020)$.

\section{Discussion}

The objective of this study was to examine short-term changes in outcomes of self-reported pain, back-specific functioning, and general health and quality of life in people who underwent a triage assessment service delivered by PTs
Table 4 General health and other variables

\begin{tabular}{|c|c|}
\hline Variable & Frequency (\%) \\
\hline \multicolumn{2}{|l|}{ Smoking status } \\
\hline Never smoked & $44 / 115(38.3)$ \\
\hline Used to smoke & 45/II5 (39.1) \\
\hline Current smoker & $26 / 115(22.6)$ \\
\hline \multicolumn{2}{|l|}{$\mathrm{BMI}^{\mathrm{a}}$} \\
\hline Normal & $30 / 115(26.1)$ \\
\hline Overweight & $44 / 115(38.3)$ \\
\hline Grade I obesity & $26 / 115$ (22.6) \\
\hline Grade 2 obesity & $8 / 115(7.0)$ \\
\hline Grade 3 obesity & $7 / 115(6.1)$ \\
\hline \multicolumn{2}{|l|}{ Other health } \\
\hline Other bone or joint problems & $72 / 115(62.6)$ \\
\hline Headaches & $42 / 115(36.5)$ \\
\hline Stomach or digestive problems & $29 / 115(25.2)$ \\
\hline Lung or breathing problems & $16 / 115$ (13.9) \\
\hline Hypertension & $14 / 115(12.2)$ \\
\hline Heart problems & $12 / 115(10.4)$ \\
\hline Diabetes & $9 / 115(7.8)$ \\
\hline Other & $18 / 115(15.7)$ \\
\hline \multicolumn{2}{|l|}{ Number of other health problems } \\
\hline 0 & $12 / 115(10.4)$ \\
\hline I & 36/II5 (31.3) \\
\hline 2 & $42 / 115(36.5)$ \\
\hline 3 or more & $25 / 115(21.7)$ \\
\hline \multicolumn{2}{|l|}{ DRAM } \\
\hline Normal & $37 / 115(32.2)$ \\
\hline At risk & $58 / 115(50.4)$ \\
\hline Distressed, somatic & $8 / 115(7.0)$ \\
\hline Distressed, depressive & $12 / 115(10.4)$ \\
\hline \multicolumn{2}{|l|}{ ODI } \\
\hline Mnimal (0-20) & $16 / 115(13.9)$ \\
\hline Moderate $(21-40)$ & $60 / 115$ (52.2) \\
\hline Severe $(4 I-60)$ & $31 / 115(27.0)$ \\
\hline Extreme disability ${ }^{\mathrm{b}}(6 \mathrm{I}-80)$ & $8 / 115(7.0)$ \\
\hline
\end{tabular}

Notes: aBMI: normal 18.5-24.9, overweight 25-29.9, Grade I obesity 30-34.9, Grade 2 obesity $35-39.9$, Grade 3 obesity $\geq 40,{ }^{50}$ bthere were no participants in the 80-100 category.

Abbreviations: BMl, body mass index; DRAM, Distress and Risk Assessment Method; ODI, Oswestry Disability Index.

with advanced orthopedic training and experience. There were significant group mean improvements in the PCS of the SF-36v2 ${ }^{\circledR}(P<0.001)$ and borderline improvements in the bodily pain scale of the SF-36 $2^{\circledR}$ and NPRS scores $(P=0.020)$ at the posttest time point.

Outcome assessments of back pain are complex and should be multidimensional. ${ }^{42}$ International groups of back pain researchers ${ }^{42,48}$ recommend considering the following domains in a standard battery of outcome measures: back-specific functioning, general well-being/generic health status, pain, satisfaction with care, and work disability (if appropriate). The types and domains of outcome measures used in this study align with the recommendations of these expert groups in terms of the exceptions of 
Table 5 Clinical descriptors of study sample

\begin{tabular}{|c|c|}
\hline Variable & Frequency (\%) \\
\hline \multicolumn{2}{|l|}{ Back pain duration } \\
\hline $0-6$ months & $15 / 114$ (13.2) \\
\hline $7-12$ months & $5 / 1 / 4(4.4)$ \\
\hline I3-24 months & $8 / 114(7.0)$ \\
\hline$>24$ months & $86 / 114(74.8)$ \\
\hline \multicolumn{2}{|l|}{ Back pain current episode } \\
\hline 0-6 months & $46 / 115(40.0)$ \\
\hline $7-12$ months & $19 / 115$ (16.5) \\
\hline 13-24 months & $18 / 115(15.7)$ \\
\hline$>24$ months & $32 / 115(27.8)$ \\
\hline \multicolumn{2}{|l|}{ Past treatment } \\
\hline Medication & $75 / 115(65.2)$ \\
\hline Massage therapy & $72 / 115(62.6)$ \\
\hline Chiropratic & $69 / 115(60.0)$ \\
\hline Physiotherapy & $63 / 115(54.8)$ \\
\hline Exercise therapy & $39 / 115$ (33.9) \\
\hline Acupunture & $30 / 115(26.1)$ \\
\hline Surgery & $4 / 115(3.5)$ \\
\hline \multicolumn{2}{|l|}{ Radiating leg symptoms } \\
\hline Absent & $16 / 115(13.9)$ \\
\hline Above knee & $31 / 115(27.0)$ \\
\hline Below knee & $68 / 115(59.1)$ \\
\hline \multicolumn{2}{|l|}{ Diagnosis $^{\mathrm{a}}$} \\
\hline Problem in back & 108/II5 (93.9) \\
\hline Medical & $1 \mathrm{I} / \mathrm{II} 5(9.6)$ \\
\hline Mechanical/degenerative other body part & $5 / 115(4.3)$ \\
\hline Spinal cord/cauda equina & $5 / 115(4.3)$ \\
\hline \multicolumn{2}{|l|}{ Back pain triage } \\
\hline Nerve root problem & $54 / 115(47.0)$ \\
\hline Serious spine pathology & $8 / 115(7.0)$ \\
\hline Not spine related & $5 / 115(4.3)$ \\
\hline \multicolumn{2}{|l|}{ Nerve root source } \\
\hline None & $52 / 115(45.2)$ \\
\hline Stenotic & $35 / 115(30.4)$ \\
\hline Discogenic & $28 / 115(24.3)$ \\
\hline \multicolumn{2}{|l|}{ Treatment recommendations } \\
\hline Referral to surgeon (any) & $23 / 115(20.0)$ \\
\hline Urgent referral to surgeon & $16 / 115(13.9)$ \\
\hline Surgeon referral + PT treatment & $6 / 115(5.2)$ \\
\hline Emergency referral to surgeon & $1 / 115(0.9)$ \\
\hline Referral to another specialist ${ }^{\mathrm{b}}$ & $11 / 115(9.6)$ \\
\hline PT treatment (any) & $73 / 115(63.5)$ \\
\hline PT treatment (only) & $67 / 115(58.3)$ \\
\hline \multicolumn{2}{|l|}{ Imaging and diagnostic tests ${ }^{a}$} \\
\hline Any imaging or other diagnostic tests ${ }^{c}$ & $38 / 115(33.0)$ \\
\hline Advanced imaging (ie, CT, MRI) & $31 / 115(27.0)$ \\
\hline X-rays & $8 / 115(7.0)$ \\
\hline No further follow-up & $2 / 115$ \\
\hline Other ${ }^{d}$ & $7 / 115(6.1)$ \\
\hline
\end{tabular}

Notes: aCategories are not mutually exclusive; btype of specialists: vascular, neurologist, pain management physician, urogynecologist, rheumatologist; cincludes X-ray, CT, MRI, blood work, bone scan; dincludes functional testing, chiropractic treatment.

Abbreviations: CT, computed tomography; MRI, magnetic resonance imaging; PT, physiotherapist.

satisfaction and work disability. Participant and referring health care provider satisfaction were ascertained at the 4-week posttest time point using quantitative and qualitative methods; however, the results are beyond the scope of this paper. ${ }^{36}$ Work disability status as an outcome measure was
Table 6 Select characteristics of 4 weeks responders versus nonresponders

\begin{tabular}{llll}
\hline Variable & Responders & Nonresponders & Significance $^{b}$ \\
\hline $\begin{array}{l}\text { Age (mean, SE) } \\
\text { LBP duration } \\
\text { (median IQR) }\end{array}$ & $52.02(1.286)$ & $46.57(6.148)$ & 0.593 \\
Female & $108.00(479)$ & $36.00(1 / 4)$ & 0.620 \\
Income (CAD) & $55 / 108(50.9)$ & $1 / 7(14.3)$ & 0.114 \\
$<30 \mathrm{~K}$ & $19 / 103(18.4)$ & $1 / 7(16.7)$ & 0.344 \\
$30-59,999 \mathrm{~K}$ & $34 / 103(33.0)$ & $4 / 7(66.7)$ & \\
$60-99,999 \mathrm{~K}$ & $30 / 103(29.1)$ & $1 / 7(16.7)$ & \\
$>$ I00K & $20 / 103(19.4)$ & $0 / 7(0)$ & \\
Education & & & \\
$<$ Grade I2 & $19 / 108(17.6)$ & $2 / 7(28.6)$ & 0.837 \\
Grade I2 & $28 / 108(25.9)$ & $2 / 7(28.6)$ & \\
Trade school & $32 / 108(29.6)$ & $2 / 7(28.6)$ & \\
University & $29 / 108(26.9)$ & $1 / 7(14.3)$ & \\
Rural residence & $75 / 108(69.4)$ & $2 / 7(28.6)$ & 0.039 \\
Internet follow-up & $46 / 108(42.9)$ & $3 / 7(42.9)$ & 1.00 \\
Diagnostic triage & & & \\
Not spine & $5 / 108(4.6)$ & $0 / 7(0)$ & 0.244 \\
Serious spine & $7 / 108(6.5)$ & $1 / 7(14.3)$ & \\
Nerve root & $53 / 108(49.1)$ & $1 / 7(14.3)$ & \\
Nonspecific & $43 / 108(39.8)$ & $5 / 7(71.4)$ & \\
back & & & \\
\hline
\end{tabular}

Notes: ${ }^{\text {Rural }}$ residence $=$ weak or no MIZ; ${ }^{\text {ccomparisons between responders and }}$ nonresponders done with independent samples $t$-test (age), Mann-Whitney $U$ test (LBP duration), Chi Square or Fisher's exact tests.

Abbreviations: SE, standard error; LBP, low back pain; IQR, interquartile range; MIZ, Metropolitan Influenced Zones.

not included in this study for a variety of reasons. People receiving workers compensation benefits in Saskatchewan can access a separate multidisciplinary team assessment process that includes triage with surgeons if required. As such, the vast majority of users of the spinal triage service are not receiving third-party-payer benefits, thus, patients that were receiving such benefits were excluded from this study. Furthermore, people with chronic back pain who were receiving third-party-payer income replacement benefits may respond differently to interventions than those that are not receiving benefits..$^{52,53}$

The results of this study suggest that many of the participants may not be representative of a typical person that presents with back-related complaints in a primary care setting. An estimated $95 \%$ of back pain cases presenting in primary care are thought to be attributable to mechanical or nonspecific back pain, less than $5 \%$ are thought to be related to true nerve root pain (arising from a disc prolapse, spinal stenosis, or surgical scarring) and only $1 \%$ of these patients are thought to have serious spinal pathologies such as tumors, infections, inflammatory conditions, or other conditions requiring urgent specialist investigation and treatment. ${ }^{11,54}$ These figures are in stark contrast to the diagnostic triage 
Table 7 Comparison of pretest and posttest outcome measures

\begin{tabular}{llll}
\hline Variable & Pretest $^{\mathrm{a}}$ & Posttest $^{\mathrm{a}}$ & Significance $^{\mathrm{b}}$ \\
\hline NPRS & $4.94(0.175)$ & $4.61(0.188)$ & 0.020 \\
ODI & $35.15(\mathrm{I} .435)$ & $33.07(\mathrm{I} .503)$ & 0.075 \\
SF_36_PF & $35.99(27.57,42.30)$ & $35.99(31.78,44.4 I)$ & 0.056 \\
SF_36_RP & $37.26(27.47,44.6 \mathrm{I})$ & $37.26(27.47,44.6 \mathrm{I})$ & 0.163 \\
SF_36_BP & $33.37(29.15,37.18)$ & $37.18(29.15,41.83)$ & 0.008 \\
SF_36_GH & $45.78(42.45,48.17)$ & $45.78(38.63,52.93)$ & 0.522 \\
SF_36_VT & $42.72(36.48,52.09)$ & $42.72(33.36,48.97)$ & 0.262 \\
SF_36_SF & $40.49(35.03,45.94)$ & $40.49(29.58,51.40)$ & 0.639 \\
SF_36_RE & $44.22(32.56,55.88)$ & $44.22(32.56,51.99)$ & 0.333 \\
SF_36_MH & $47.19(38.74,52.82)$ & $47.19(38.74,52.82)$ & 0.202 \\
SF_36_PCS & $35.09(0.842)$ & $37.33(0.821)$ & 0.000 \\
SF_36_MCS & $47.79(40.53,55.87)$ & $48.26(37.40,55.60)$ & 0.059 \\
\hline
\end{tabular}

Notes: aMean (SE) reported for normally distributed variables, median (IQR) reported for non-normally distributed variables; ba Bonferonni correction (ie, 0.05/ number of comparisons) was applied to alpha to protect against a type I error due to multiple comparisons. Thus the new alpha level is: $0.05 / 12=0.004$.

Abbreviations: SE, standard error; IQR, interquartile range; NPRS, Numeric Pain Rating Scale; ODI, Oswestry Disability Index; SF_36_PF, SF36 Physical Function subscale; SF_36_RP, SF_36 Role Physical subscale; SF_36_BP, SF36 Bodily Pain subscale; SF 36 GH, SF36 General Health subscale; SF 36 VT, SF36 Vitality subscale; SF_36_SF, SF36 Social Function subscale; SF_36_RE, SF36 Role Emotional subscale; SF_36_MH, SF36 Mental Health subscale; SF_36_PCS, SF36 Physical Component Summary; SF_36_MCS, AF36 Mental Component Summary.

categorization of the participants in this study (ie, $42 \%$ mechanical spine, $47 \%$ nerve root, and $7 \%$ serious spine pathology, see Table 5). Furthermore, the study participants primarily had chronic longstanding symptoms $(75 \%$ had $>24$ month total symptom duration), complex clinical presentations (ie, high proportion of below knee symptom referral, high proportion of other chronic conditions), high perceived disability, and psychological risk factors (according to the DRAM). Therefore, the people using the service likely represent more complex spinal problems than may typically be seen in a primary care setting, ${ }^{55,56}$ as might be expected from patients who are referred for a surgical opinion. The participants also reported low overall general well being, compared to healthy normative populations and disease-specific norms of people with back pain/sciatica. ${ }^{43}$ For example, mean or median scores on the SF-36v2 PCS and MCS from a population-based study of people in the United States with back pain/sciatica were 45.70 (PCS mean) and 50.40 (MCS median), ${ }^{43}$ which are much higher (ie, better) than the baseline participant scores of 35.09 (PCS mean) and 47.79 (MCS median) in this study. Given the high proportion of people with chronic problems, nerve root, and other serious spinal pathologies in this cohort, the higher baseline levels of reduced perceived psychosocial and physical quality of life are not surprising.

The spinal triage program is providing a service to the patients and to the primary care providers by sending a detailed report and management plan to the referring care provider. The triage service is a model of care that operates at the interface between primary and secondary care; therefore, the characteristics of patients referred to this service and the patterns of referral sources potentially reflect unmet needs at the primary care level. LBP is a common reason for seeking care at the primary care level. A recent study by Jordan et al found that a quarter of all consultations in a UK physician-based primary care setting were for musculoskeletal problems, and the back (20\%, low back $14 \%)$ was the most common reason. ${ }^{57}$ In Canada, people with chronic back pain report significantly greater use of their family physician, physiotherapy, and chiropractic services than those without back pain. ${ }^{6,58}$ Those with co-morbidities such as arthritis or depression are most likely to consult a family physicians and/or PTs. ${ }^{58}$ Further research is needed to fully understand the impact that a spinal triage program may have on meeting the needs and easing the burden of primary care providers by assisting with diagnosis and management of patients who present with chronic and/or complex spinal problems. Furthermore, the impact of reduced access to local health care services on participant outcomes is an important area for further research given the high proportion of patients who are referred from rural regions.

By assessing outcomes relatively soon after the triage assessment was performed, we hoped to gain insight into whether the assessment process itself affected participant outcomes. Note that the assessment did not consist of any PT treatment per se, other than education regarding the assessment findings and a consultation regarding the plan of action for management, which included a summary in lay-terms of what was to be included in the assessment report. Despite the chronic and complex baseline characteristics of the sample, there was a mean overall significant improvement in the SF-36 PCS and borderline significant improvements in the bodily pain subscale of the SF-36 and the NPRS. It is likely that the participants did not have time to embark fully on any treatment or management recommendations during the 4 weeks after the assessment; therefore, any improvements in outcomes could be related to the assessment itself as a type of intervention. A spinal triage assessment program delivered by PTs can be viewed as a complex intervention that may have the potential to influence a wide range of patient-related outcomes. ${ }^{32}$ Complex interventions may contain a number of different elements that act independently or interdependently; therefore, it is difficult to identify the precise mechanisms that contribute to outcomes. ${ }^{31}$ 
One potential mechanism of action is the education and reassurance that patients receive as part of the triage assessment process. Up to $50 \%$ of back pain patients presenting to primary care suspect that they have a serious pathology. ${ }^{11,59}$ People who experience pain, particularly when the precise cause cannot be determined, often feel hopeless and helpless. Additionally, the inability to obtain timely or effective relief for their pain may result in further depression and anxiety. ${ }^{60}$ This, in turn, can lead to increased perceived pain and disability ${ }^{61}$ Feelings of uncertainty and insecurity regarding fear of the unknown (ie, having a diagnosis of "nonspecific low back pain," or having no clear diagnosis at all) also have the potential to hamper any attempts at treatment and potential recovery. ${ }^{54}$ Both the assessing and consulting PTs in the triage assessment play an important role in reassuring the patient about their symptoms and how they may be related to potential underlying conditions. Furthermore, given that the main output of the assessment is a detailed report that outlines a plan of action for subsequent management, investigation, and follow-up, the triage method likely provides or enhances the patient's sense of certainty and control. The role of reassurance in interactions between health care providers and patients with chronic pain is a complex process that requires further research ${ }^{62}$ that may help to elucidate the role of reassurance and education in the spinal triage assessment process and other potential mechanisms for why improvements in outcomes occur.

This study's findings should be interpreted in light of its limitations. The main limitations are related to design, response rate, and analysis issues. The primary limitation is the lack of a control or comparison group. The absence of a control group can result in many potential forms of bias (ranging from history, maturation, testing, or selection); ${ }^{63}$ therefore, the findings should be interpreted with caution. For example, although there was an overall mean significant improvement in some outcome measures, the improvements cannot be attributed to the triage assessment itself with any certainty. A further limitation is the bias that may have been introduced due to the loss of participants in the follow-up procedure and the lack of response of referring care providers. Despite having a relatively high follow-up response rate $(93.9 \%)$, the nonrespondents may have differed significantly in ways that were not mentioned by the respondents. Furthermore, we cannot be certain that the participants did not embark on any recommended treatment during the interval of the assessment and the 4-week follow-up. This time point was chosen for pragmatic reasons, mainly to allow time for the assessment report to be sent to the referring health care provider. The majority of the management recommendations were arranged through the referring care provider; therefore, we assumed that treatment was not initiated in most cases. Finally, the application of a Bonferroni correction to the alpha level in order to protect against the chance of making a type 1 error (ie, false positive) may have resulted in levels of statistical significance that were too rigid, thus, increasing the likelihood of making a type 2 or false negative error. In other words, there was a danger of rejecting potentially valid variables that did not reach the adjusted level of significance.

The aims of this study were primarily exploratory and further research is needed to fully understand the long-term impacts that a spinal triage service delivered by PTs can have as well as the potential mechanism(s) by which improvements can occur. A further study examining outcomes at 6 and 12 months following the assessment is currently under way. When this study is complete, we will be able to ascertain whether short-term improvements following the assessment were sustainable, or not, and which factors may influence sustainability. Variables such as whether treatment recommendations were carried out, perceived access to recommended conservative management providers, and the type of diagnosis will be included in the next analysis. The examination of potential predictors of success (or deterioration) of patient outcomes using a biopsychosocial model may also help to shed light on why some people improve and some do not, while helping to identify potential gaps in the care pathway. Mixed methods research, which combines quantitative and qualitative techniques, is recommended in order to gain a broader understanding of complex interventions like the spinal triage service. ${ }^{31}$ As such, further research using quantitative and qualitative methods would contribute to generating a program effect theory ${ }^{64,65}$ or a program logic model ${ }^{66}$ to explore/ explain why there was improvement at the short-term time point. Further research could test the validity of such a theory. This study, which focuses on patient-related outcomes only, does not include an examination of the cost and economic implications associated with the triage program. The participating STAS surgeons have used this model for several years; therefore, we were unable to access an equivalent control group to compare wait times in the STAS versus "traditional" referral pathways to the surgeons. Thus, further research that examines the cost implications and compares the effectiveness and efficiency of different models of care and service delivery is needed.

\section{Conclusion}

Although the specific reasons are unclear, a spinal triage assessment program delivered by PTs can be viewed as a complex intervention that may have the potential to affect a wide range of patient-related outcomes. This study demonstrated 
that, despite the chronic and complex baseline characteristics of the sample, there were significant group mean short-term improvements in the PCS of the SF-36v2 ${ }^{\circledR}(P<0.001)$ of participants undergoing a spinal triage assessment performed by PTs. Further research is needed to examine the long-term outcomes and explore potential mechanisms of improvements using a biopsychosocial framework.

\section{Acknowledgments}

Brenna Bath was supported by the following funders during the course of this research: Canadian Institutes of Health Research (CIHR) Fellowship in Knowledge Translation, Public Health and the Agricultural Rural Ecosystem CIHR Graduate Training Program, and the Western Regional Training Centre for Health Services Research CIHR Graduate Training Program. Operational funding for this research was provided by Bourassa and Associates Rehabilitation Centre, Saskatoon, Saskatchewan, Canada. The authors are grateful to the surgeons and PTs associated with the STAS for their support of this project. We are also thankful to Stacey Lovo Grona for her assistance with clinical data collection, and to Cindy Robb for her assistance with data entry and study administration. Finally, we would like to thank Bonnie Janzen, Liz Harrison, and Alice Aiken for suggestions on earlier versions of this manuscript.

\section{Disclosure}

The authors report no conflicts of interest in this work.

\section{References}

1. Andersson GB. Epidemiological features of chronic low-back pain. Lancet. 1999;354(9178):581-585.

2. Hestbaek L, Lenoeuf-Yde C, Manniche C. Low back pain: What is the long-term course? A review of studies of general patient populations. Eur Spine J. 2003;12(2):149-165.

3. Lawrence RC, Felson DT, Helmick CG, et al. Estimates of the prevalence of arthritis and other rheumatic conditions in the United States. part II. Arthritis Rheum. 2008;58(1):26-35.

4. Katz JN. Lumbar disc disorders and low-back pain: Socioeconomic factors and consequences. J Bone Joint Surg Am. 2006;88(Suppl 2): $21-24$.

5. Gandjour A, Telzerow A, Lauterbach KW, INTERCARE International I. European comparison of costs and quality in the treatment of acute back pain. Spine. 2005;30(8):969-975.

6. Lim KL, Jacobs P, Klarenbach S. A population-based analysis of healthcare utilization of persons with back disorders: Results from the Canadian Community Health Survey 2000-2001. Spine. 2006;31(2): 212-218.

7. Hadlow AT. Back pain: A problem of referral. J Bone Joint Surg Br. 2003;85-B(Supp_III):208.

8. MacKay C, Canizares M, Davis A, Badley E. Health care utilization for musculoskeletal disorders. Arthritis Care Res. 2010;62(2):161-169.

9. Canizares M, MacKay M, Davis A, Mahomed N, Badley E. Orthopaedic surgery in Ontario in the era of the wait time strategy. Arthritic Community Research and Evaluation Unit. Report No: 07-02. 2007.
10. Mayman D, Yen D. Maximizing use of a surgical clinic for referrals of patients having back problems. Can J Surg. 1999;42:117-119.

11. Waddell G. Diagnostic triage. In: The Back Pain Revolution. Second ed. Toronto: Churchill Livingstone; 2004:9-26.

12. Waddell G. Epilogue. In: The Back Pain Revolution. Second ed. Toronto: Churchill Livingstone; 2004:457-459.

13. Daker-White G, Carr AJ, Harvey I, et al. A randomised controlled trial. Shifting boundaries of doctors and PTs in orthopaedic outpatient departments. J Epidemiol Community Health. 1999;53(10): 643-650.

14. Hattam P. The effectiveness of orthopaedic triage by extended scope physiotherapists. Clin Govern Int J. 2004;9(4):244-252.

15. Aiken AB, Harrison MM, Atkinson M, Hope J. Easing the burden for joint replacement wait times: The role of the expanded practice physiotherapist. Healthcare Quarterly. 2008;11(2):62-66.

16. Sarro A, Rampersaud YR, Lewis S. Nurse practitioner-led surgical spine consultation clinic. JAdv Nurs. 2010;66(12):2671-2676.

17. Childs JD, Whitman JM, Sizer PS, Pugia ML, Flynn TW, Delitto A. A description of physical therapists' knowledge in managing musculoskeletal conditions. BMC Musculoskelet Disord. 2005;6:32.

18. Moore JH, Goss DL, Baxter RE, et al. Clinical diagnostic accuracy and magnetic resonance imaging of patients referred by physical therapists, orthopaedic surgeons, and nonorthopaedic providers. J Orthop Sports Phys Ther. 2005;35(2):67-71.

19. Boissonnault WG. Primary Care for the Physical Therapist: Examination and Triage. Toronto, Canada: Elsevier Ltd; 2005.

20. Hattam $P$, Smeatham A. Evaluation of an orthopaedic screening service in primary care. Br J Clin Govern. 1999;4(2):45-49.

21. Jibuike OO, Paul-Taylor G, Maulvi S, Richmond P, Fairclough J. Management of soft tissue knee injuries in an accident and emergency department: The effect of the introduction of a physiotherapy practitioner. Emerg Med J. 2003;20(1):37-39.

22. Hourigan PG, Weatherley CR. Initial assessment and follow-up by a physiotherapist of patients with back pain referred to a spinal clinic. J R Soc Med. 1994;87(4):213-214.

23. The Chartered Society of Physiotherapy. Making physiotherapy count. Society's Sharing Effective Physiotherapy Practice Project. London, UK: The Chartered Society of Physiotherapy; 2004.

24. Aiken AB, McColl M. Interprofessional healthcare: A common taxonomy to assist with understanding. J Allied Health. 2009;38: 92-96.

25. O'Cathain A, Froggett M, Taylor MP. General practice based physiotherapy: Its use and effect on referrals to hospital orthopaedics and rheumatology outpatient departments. Br J Gen Pract. 1995;45(396): 352-354.

26. Hendriks EJ, Kerssens JJ, Nelson RM, Oostendorp RA, van der Zee J. One-time physical therapist consultation in primary health care. Phys Ther. 2003;83(10):918-931.

27. NHS Modernisation Agency, Department of Health. Improving orthopaedic services: A guide for clinicians, managers and service commissioners. London: NHS Modernisation Agency and Department of Health; 2002.

28. Alberta Bone and Joint Health Institute. Alberta hip and knee replacement pilot project. Scientific Evaluation Report. Alberta Bone and Joint Health Institute; 2007.

29. Weatherley CR, Hourigan PG. Triage of back pain by physiotherapists in orthopaedic clinics. J R Soc Med. 1998;91(7):377-379.

30. McPherson K, Kersten P, George S, et al. A systematic review of evidence about extended roles for allied health professionals. $J$ Health Serv Res Pol. 2006;11(4):240-247.

31. Campbell M, Fitzpatrick R, Haines A, et al. Framework for design and evaluation of complex interventions to improve health. BMJ. 2000;321:694-696.

32. Kersten P, McPherson K, Lattimer V, George S, Breton A, Ellis B. Physiotherapy extended scope of practice- who is doing what and why? Physiother. 2007;93:235-242. 
33. Edwards I, Jones M, Higgs J, Trede F, Jensen G. What is collaborative reasoning? Adv Physiother. 2004;6:70-83.

34. Shadish WR, Cook TD, Campbell DT. Experimental and QuasiExperimental Designs for Generalized Causal Inference. New York: Houghton Mifflin Company; 2001.

35. Dillman DA, Smyth JD, Christian LM. Internet, Mail and Mixed-Mode Surveys: The Tailored Design Method. 3rd ed. Hoboken, New Jersey: John Wiley \& Sons Inc; 2009.

36. Bath B, Janzen B. Patient and referring health care provider satisfaction with a physiotherapy spinal triage assessment service. J Multidiscip Healthc. 2012;5:1-15.

37. Jensen MP, Turner JA, Romano JM. What is the maximum number of levels needed in pain intensity measurement? Pain. 1994;58(3):387-392.

38. Childs JD, Piva SR, Fritz JM. Responsiveness of the numeric pain rating scale in patients with low back pain. Spine. 2005;30(11):1331-1334.

39. Fairbank JC, Couper J, Davies JB, O'Brien JP. The Oswestry low back pain disability questionnaire. Physiother. 1980;66(8):271-273.

40. Fairbank JC, Pynsent PB. The Oswestry disability index. Spine. 2000;25:2940-2952.

41. Roland M, Fairbank JC. The Roland-Morris disability questionnaire and the Oswestry disability questionnaire. Spine. 2000;25:3115-3124.

42. Deyo RA, Battie M, Beurskens AJ, et al. Outcome measures for low back pain research. A proposal for standardized use. Spine. 1998;23(18):2003-2013.

43. Ware JEJ, Kosinski M, Bjorner JB, Turner-Bowker DM, Gandek B, Maruish ME. User's Manual for the SF-36v2 Health Survey. 2nd ed. Lincoln, RI: QualityMetric Incorporated; 2007.

44. Ware JE, Sherbourne C. The MOS 36-item short-form survey (SF-36): I. Conceptual framework and item selection. Med Care. 1992;30:473-483.

45. Brazier JE, Harper R, Jones NM, et al. Validating the SF-36 health survey questionnaire: New outcome measure for primary care. $B M J$. 1992;305(6846):160-164.

46. Garratt AM, Ruta DA, Abdalla MI, Buckingham JK, Russell IT. The SF36 health survey questionnaire: An outcome measure suitable for routine use within the NHS? BMJ. 1993;306(6890):1440-1444.

47. Beaton DE, Hogg-Johnson S, Bombardier C. Evaluating changes in health status: Reliability and responsiveness of five generic health status measures in workers with musculoskeletal disorders. J Clin Epidemiol. 1997;50(1):79-93.

48. Bombardier C. Outcome assessments in the evaluation of treatment of spinal disorders: Summary and general recommendations. Spine. 2000;25(24):3100-3103.

49. Jenkinson C, Stewart-Brown S, Peterson S, Paice C. Assessment of the SF-36 version 2 in the United Kingdom. $J$ Epidemiol Community Health. 1999;53:45-50.

50. American College of Sports Medicine. ACSM's Guidelines for Exercise Testing and Prescription. 5th Edition ed. Baltimore, USA: Williams \& Wilkins; 1995
51. Main CJ, Wood PL, Hollis S, Spanswick CC, Waddell G. The Distress and Risk Assessment Method. A simple patient classification to identify distress and evaluate the risk of poor outcome. Spine. 1992;17(1):42-52.

52. Carreon LY, Glassman SD, Kantamnene NR, Mugavin MO, Djurasovic M. Clinical outcomes after posterolateral lumbar fusion in workers' compensation patients: A case control study. Spine. 2010;35(19):1812-1817.

53. Atlas SJ, Tosteson TD, Blood EA, Skinner JS, Pransky GS, Weintein JN. The impact of workers' compensation on outcomes of surgical and nonoperative therapy for patients with a lumbar disc herniation. Spine. 2009;35(1):89-97.

54. Greenhalgh S, Selfe J. Red Flags: A Guide to Identifying Serious Pathology of the Spine. Toronto: Churchill Livingstone; 2006.

55. Dunn KM, Jordan KP, Croft PR. Contribution of prognostic factors for poor outcome in primary care low back pain patients. Eur J Pain. 2011;15:313-319.

56. Hall H, McIntosh G, Boyle C. Effectiveness of a low back classification system. Spine J. 2009;9:648-657.

57. Jordan KP, Kadam KD, Haywards R, Porcheret M, Young C, Croft P. Annual consultation prevalence of regional musculoskeletal problems in primary care: An observational study. BMC Musculoskelet Disord. 2010;11(144):1471.

58. Bath B, McCrosky J, Janzen B, Pahwa P. Healthcare utilization by people with chronic back disorders: Analysis of the 2008 Canadian Community Health Survey. Proceedings of the Canadian Association of Health Services and Policy Research Annual Conference; May 9-12, 2011; Halifax, Canada.

59. von Korff M, Moore JC. Stepped care for back pain: Activating approaches for primary care. Annals of Internal Medicine. 2001;134: 911-917.

60. Rubin DI. Epidemiology and risk factors for spine pain. Neurol Clin. 2007;25(2):353-371.

61. Waddell G. The biopsychosocial model. In: The Back Pain Revolution. Second ed. Toronto: Churchill Livingstone; 2004:265-282.

62. Linton SJ, McCracken LM, Vlaeyen JW. Reassurance: Help of hinder in the treatment of pain. Pain. 2008;134:5-8.

63. Hennekens CH, Buring JE. Epidemiology in Medicine. New York, USA: Lipincott Williams \& Wilkins; 1987.

64. Issel LM. Health Program Planning and Evaluation: A Practical, Systematic Approach for Community Health. London, UK: Jones and Bartlett Publishers International; 2004.

65. Hodges BC, Videto DM. Assessment and Planning in Health Programs. Mississauga, ON: Jones and Bartlett Publishers Canada; 2005.

66. Dwyer JM, Makin S. Using a program logic model that focuses on performance measurement to develop a program. Can J Public Health. 1997;88(6):421-425.

67. du Plessis V, Beshiri R, Bollman R, Clemenson H. Definitions of "rural" agricultural and rural working paper series no 61. Ottawa: Statistics Canada Agriculture Division; 2002.
Patient Related Outcome Measures

\section{Publish your work in this journal}

Patient Related Outcome Measures is an international, peer-reviewed, open access journal focusing on treatment outcomes specifically relevant to patients. All aspects of patient care are addressed within the journal and practitioners from all disciplines are invited to submit their work as well as healthcare researchers and patient support groups. Areas covered will

\section{Dovepress}

include: Quality of life scores; Patient satisfaction audits; Treatment outcomes that focus on the patient; Research into improving patient outcomes; Hypotheses of interventions to improve outcomes; Short communications that illustrate improved outcomes; Case reports or series that show an improved patient experience; Patient journey descriptions or research. 